\title{
UPAYA MENANGGULANGI PERILAKU BIBLIOCRIME DI PERPUSTAKAAN UNIVERSITAS ISLAM NEGERI SUMATERA UTARA MEDAN
}

\author{
Dr. Muhammad Dalimunte, S.Ag., SS., M.Hum \\ Nurhayani, S.Ag., SS., M.Si \\ Muhammad Riandy Arsin Siregar
}

\begin{abstract}
Abstrak
Jurnal ini mengulas dan membahas tentang perilaku bibliocrime, seperti pencurian, perobekan, vandalisme, mutilasi dan peminjaman tak sah di Perpustakaan UIN-SU dan beberapa faktor yang melatarbelakangi kejahatan dan juga dibahas kerugian finansial maupun kerugian sosial yang ditimbulkannya. Jadi untuk itu perpustakaan Universitas Islam Sumatera Utara mempunyai upaya untuk menanggulanginnya di antaranya peraturan dan sanksi, himbauan, pendidikan pemakai, juga sistem keamanan. Dalam penelitian ini menggunakan pendekatan kualitatif, dan juga terdapat 12 orang yang menjadi infoman dalam penelitian .
\end{abstract}

Kata Kunci: Bibliocrime, Bahan Pustaka, Perpustakaan Universitas Islam Sumatera Utara.

\begin{abstract}
This journal reviews and discusses bibliocrime behavior, such as theft, tearing, vandalism, Unauthorized Borrowing at the library of State Islamic University of North Sumatra-Medan and some the factors behind the crime and also dicusees about financial and social losses. So the library of the of State Islamic University of North Sumatra-Medan has done same efforts to resolve among the rules and sanctions, mandates, user education, and security systems. This research applies a qualitative approach, and involves 12 informants as the sources of needed infortmantion.
\end{abstract}

Keywords: Bibliocrime, library material, the library of State Islamic University of North Sumatra-Medan 


\section{Pendahuluan}

Perpustakaan sebagai lembaga pusat informasi hadir untuk memenuhi kebutuhan masyarakat, sebagaimana yang dikemukan oleh (Aprilia \& Sumaryato, 2013, pp. 1-2) yang mengatakan "Perpustakaan berperan dalam menyediakan berbagai sumber ilmu pengetahuan yang dibutuhkan masyarakat melalui koleksi yang dimilikinya. Namun kebaikan dan ketulusan perpustakaan itu terkadang disalagunakan oleh pemustaka yang bekunjung karena melakukan berbagai macam tindakan yang merusak berbagai koleksi pencurian, perobekan, vandalisme, mutilasi dan peminjaman tak sah.

Kondisi demikian telah menyebabkan kekacauan di lingkungan perpustakaan dan membuat citra dari lembaga informasipun menjadi tercoreng. Padahal semestinya bahan pustaka tersebut hanyalah benda mati tak bisa melakukan apapun, sehingga tak perlu untuk dijahati malahan harus disayangi dan dirawat, sebagaimana dipaparkan oleh (Sulistyo-Basuki, 1991, p. 272) yang menyatakan bahwa "Manusia dalam hal ini pemustaka perpustakaan dapat menjadi lawan atau kawan". Pemakai tertentu bisa menjadi kawan jikalau dalam mempergunakan koleksi bahan pustaka itu dengan bijaksana tanpa mencederai, tetapi sebaliknya bisa juga menjadi musuh yang sangat berbahaya jika mempergunakannya dengan perilaku kasar tanpa kasih sayang yang pada akhirnya dapat merugikan.

Fenomena ini terjadi dipicu oleh beberapa faktor diantarnya adalah diataranya adalah layanan terbuka yang memudahkan para pemuska untuk mengambil koleksi yang di inginkannya langsung ke rak tampa bantuan dari pemustaka, sehingga koleksipun menjadi berantakan, menjadikan pemustaka lain yang baru datangpun tidak leluasa untuk mencari.

Terkait dengan kondisi ini peneliti tertarik kepada penelitian yang pernah dilakukan oleh (Obiagwu, 1992, pp. 295-296) di perpustakaan Universitas Port Harcourt (Uniport) di Nigeria dan King Fahd University of 
Petroleum dan Minerals (KFUPM) di Arab- Saudi yang menyajikan hasil penelitian tentang perilaku. Hasil penelitian sebanyak 2,22\% dalam mutilasi, sedangkan pada peminjaman tidak sah tak kurang dari 50,15\%, sementara $0,8 \%$ melakukan pencurian terhadap bahan pustaka.

Atas penelitian tersebutlah perpustakaan adalah area yang sangat renta pada kejahatan terkhusus bibliocrime. Maka diperlukanlah tindakan preventif guna membendung tindakan tersebut agar tidak menimbulkan kerusakan yang lebih parah.

Seperti halnya Universitas Islam Negeri Sumatera Utara (UIN-SU) yang merupakan salah satu PTN di Sumatera Utara, mempunyai sebuah perpustakaan Universitas yang menyediakannya berbagai macam koleksi, guna untuk mendukung tri drama perguruan tinggih. Meski begitu perpustakaan Universitas Islam Negeri Sumatera Utara (UIN-SU) masih sarat dengan perilaku bibliocrime. Sebagai contoh pada pengamatan awal peneliti melihat buku-buku yang tadi sudah tersusun rapi di rapih di rak lama kelamaan menjadi rusak bahkan sampai ke lantai, sehingga kondisi ini menyebabkan areal perpustakaan tidak kondusif lagi.

Berdasarkan latar belakang inilah peneliti tertarik melakukan penelitian untuk mengetahui upaya apa yang dilakukan perpustakaan Universitas Islam Negeri Sumatera Utara dalam menanggulangi kejahatan bibliocrime, guna bahan penulisan skripsi peneliti berjudul : Upaya Menanggulangi Perilaku Bibliocrime di Perpustakaan Universitas Islam Negeri Sumatera Utara.

\section{$1.1 \quad$ Rumusan Masalah}

Adapun yang menjadi rumusan masalah dalam penelitian ini adalah sebagai berikut :

1. Bagaimana upaya menanggulangi perilaku bibliocrime di perpustakaan UIN-SU ?

2. Apa saja kendala yang dihadapi dalam penanggulangan perilaku bibliocrime di perpustakaan UIN-SU ? 


\subsection{Tujuan Penelitian}

Mengacu kepada latar belakang dan rumusan masalah di atas, maka tujuan penelitian ini adalah sebagai berikut :

1. Untuk mengetahui upaya menanggulangi perilaku bibliocrime di perpustakaan UIN-SU.

2. Untuk mengetahui kendala-kendala dalam menanggulangi perilaku bibliocrime di Perpustakaan UIN-SU. 


\section{Pembahasan}

Pustakawan sebagai pengelola harus pandai mengenal sifat dan karakter dari tiap pemustaka yang berkunjung ke perpustakan, karena itulah penanganan dari macam- macam pemustaka haruslah berbedabeda, sehingga terciptalah layanan prima yang akan berdampak pada berkurangnya kejahatan di dalam perpustakaan yang biasa disebut dengan bibliocrime .

Kata bibliocrime sendiri mungkin terdengar asing ditelinga kita, tetapi walaupun begitu bibliocrime sendiri mempunyai arti kejahatan di perpustakaan karena tindakkanya yang merusak koleksi.

Terdapat empat jenis kejahatan bibliocrime di dalam perpustakaan yaitu:

- Pencurian

Pencurian bisa terjadi di mana saja dan kapan saja, termasuk di perpustakaan. Pencurian di perpustakaan biasanya menyasar berbagai barang-barang yang ada di perpustakaan, dan pelaku tidak memikirkan dampaknya bagi orang lain atau khalayak luas, yang penting kebutuhannya terpenuhi.

Dalam perilaku pencurian khususnya di lingkungan perpustakaan menurut Bean (1992) dikutip (Listiayani, 2010, p. 14) terdapat dua penggolongan pencurian yaitu :

a. Pencurian Sistematis

Pencurian sistematis adalah jenis pencurian secara langsung, pencurian yang direncanakan, dimana seseorang datang ke perpustakaan dengan niat mencuri.

b. Pencurian tidak Sistematis

Pencurian tidak sistematis adalah pencurian yang tidak direncanakan, yaitu dengan meminjam koleksi sesuai dengan prosedur yang sah, namun dalam jangka waktu yang telah ditentukan koleksi yang dipinjam tidak pernah dikembalikan lagi.

- Mutilation (Perobekan) 
Mutilation adalah sebuah perilaku yaitu berupa perobekan, penghilangan, pemotongan, ilustrasi dari suatu ensiklopedia, majalah jurnal, buku, dan lain-lain tanpa atau dengan menggunakan alat. Senada dengan itu (Obiagwu, 1992, p. 291) Mutilation is the excision of articles and illustration from journal, books, encyclopedias, etc, yang artinya mutilasi adalah eksisi artikel dan ilustrasi dari jurnal, buku, ensiklopedi, dll. "

Perbuatan mutilasi ini begitu merugikan karena merusak kandungan isi buku, sehingga dapat membuat transfer ilmu menjadi terhambat. Perobekan ini banyak terjadi sehingga mengakibatkan pemustaka harus melakukan tidakan penyiangan (weeding) guna memperpanjang usia dari bahan pustaka.

- Vandalisme

Dalam kamus kepustakawan Indonesia yang disusun oleh(Lasa Hs \& Suciati, 2017, p. 678) menyatakan bahwa vandalisme di perpustakaan memiliki bermacam-macam jenis yaitu menambah (memberikan garis bawah, memberikan tanda tertentu pada halaman buku, stabile,dll), mengurangi (menyobek, melepas halaman) merusak (melipat halaman buku, membaca buku sambil merokok sehingga percikan api mengenai buku, menyimbunyikan buku tertentu, merusak sistem OPAC atau mencorek-corek pentunjuk perpustakaan. Maka tindakan vandalisme begitu merajalela di perpustakaan menyasar tidak hanya koleksi tetapi fasilitas penunjangnya juga.

- Unauthorized Borrowing (Peminjaman Tidak Sah)

Menurut (Obiagwu, 1992, p. 291)bahwa:"Unauthorized borrowing is synonymous with illegal or convenience borrowing", yang artinya pinjaman tanpa nama adalah indentik dengan pinjaman ilegal. Sementara menurut (Adrimon \& Nalisa, 2013, p. 
1) "Unauthorized borrowing (peminjaman tidak sah) yaitu kegiatan pemustaka yang melanggar aturan peminjaman".

Pernyataan tersebut dapat diartikan bahwa perilaku peminjaman tidak sah (unauthorized borrowing) adalah suatu tidakan peminjaman koleksi perpustakaan yang tidak menaati aturan sehingga dapat merugikan baik lembaga perpustakaan sendiri, terlebih-lebih lagi pemustaka yang sedang membutukan informasi. Oleh karena itu pengamanan dan pemberian pemahaman amat perlu dilakukan dalam menjaga ketentraman perpustakaan khusunya bahan pustaka.

Namum keempat jenis kejahatan Bibliocrime tidaklah terjadi begitu saja, melainkan ada faktor - faktor yang melatar belakanginya, menurut Lincoln (1984) (Listiayani, 2010, p. 29) ada Sembilan faktor yang melatarbekangi kejahatan Bibliocrime yaitu kemudahan aksess, oleksi yang diminati, Usia Pemustaka, Jam Buka Oprasional, Fasilitas fotocopy, Kurangnya pengamanan, Tidak adanya pelatihan staf perpustakaan dalam pencegahan penyalahgunaan koleksi, desain gedung dan ruang perpustakaan peraturan perpustakaan.

Dari tindakan bibliocrime ini pastinya menimbulkan kerugian yaitu finansial maupun sosial. Maka untuk itu di perlukanlah upaya penaggulan agar nantinya tindakan bibliocrime berkurang di pepustakaan. Untuk menggulangi tindakan bibliocrime ada beberapa cara yaitu, pengaturan tata ruang perpustakaan, penerapan sangsi tegas, pelatihan untuk pustakawan dan pemustaka, penerapan sistem keamanan.

\section{Metodelogi Penelitian}

Pada penelitian ini berlokasi di perpustakaan Universitas Islam Negeri Sumatera Utara Medan dan mengunakan metode kualititif yang berarti peneliti hanya mengambarkan keadaan sebenarnnya terkait 
tindakan bibliocrime. Guna mendapatkan data penelitian yang dapat dipertanggujabakan peneliti penggunaka teknik pengumpulan data yaitu observasi, dokumentasi serta wawacara.

Dalam proses wawancara terdapat beberapa informan yang peneliti pilih dalam penelitian ini adalah sebagai berikut:

a. Kepala Perpustakaan, karena kedudukannya sebagai pimpinan mengetahui secara keseluruhan tentang kondisi dan keberadaan Perpustakan UIN-SU, khususnya mengenai perilaku bibliocrime.

b. Pustakawan, karena salah satu pihak yang bersinggungan langsung dengan pemustaka dan bahan pustaka dalam memberikan pelayanan.

c. Satpam, karena sebagai pihak yang turut membantu pelaksanan tugas pustakawan dalam menjaga ketertiban dan keamanan lingkungan perpustakaan.

d. Pemustaka, karena sebagai pihak yang langsung menggunakan fasilitas perpustakaan UIN-SU.

e.

Alasan Peneliti memilih para informan ini karena mereka adalah pelaku yang berinsteraksi langsung di lokasi penelitian.

\section{PENYAJIAN DAN ANALISIS}

Dalam penelitian ini terdapat 12 orang infoman yang terdiri atas enam laki-laki dan eman perempuan yang semuanya telah memaparkan infomasi terkait dengan penelitian ini . Sehingga penelitipun menemukan empat tindakkan bibliocrime yaitu:

- Theft (Pencurian)

Pencurian yang ada diperpustakaan UIN Sumatera Utara tidak hanya menyasar berbagai koleksi tetapi juga barangbarang pribadi milik pemustaka dan pustakawan seperti dompet tas dan HP. 
- Mulatilation (Perobekan)

Perobekan adalah sesuatu tindakan pememisahan antara satu bagian dengan bagian lainnya. Perilaku perobekan sendiri bisa membawa efek yang baik tetapi juga bisa mempunyai dampak negatif ,apalagi jikalau perobekan itu terkait dengan buku seperti yang terjadi di perpustakaan UIN-SU . Buku- buku dirobek pada sebagian bab dalam buku sehingga menghalangi tersebarnya khazanah ilmu pengetahuan.

- Vandalisme (Vandalisme)

Vandalisme adalah tindakan pencoretan yang merusak keindahan baik fasilitas umum maupun benda, seperti halnya buku-buku yang tersedia di perpustakaan UIN-SU, kerap kali menjadi sasaran pencoretan pada bagian halaman yang berisikan teori dari para ahli, tujuan agar mereka lebih memhami teori itu sehingga tinta penapun kerap kali mengores di lembaran buku-buku perpustakaan. Seperti pendapat C. Hedrick dan M. Murfin dikutip(Ajala \& Oyeboade, 2014, p. 23) dari menyatakan bahwa bahan pustaka rentan menjadi objek pemutilasian dan juga pencoretan di karena pemustaka mempunyai kebiasaan untuk mencatat sehingga agar lebih paham ia menandai buku.

- Unauthorized Borrowing (Peminjaman Tidak Sah)

Peminjam tak sah yang sering terjadi di perpustakaan UINSU yaitu peminjaman koleksi diluar batas dari aturan yang ada. Aturan yang ada memberikan kelonggaran kepada pemustaka untuk meminjam dalam jangka waktu seminggu dan dapat diperpanjang selama satu minggu berikutnya.

Keleluasaan yang diberikan perpustakaan itu kebanyakan di salahgunakan oleh pemustaka karena menggap remeh denda Rp.500, hari/ buku. Sehingga hal tersebut menhalangi pemustaka lain untuk memperoleh infomasi dari buku tersebut, dan tidak hanya itu saja adanya peminjaman tak sah tampa 
kartu anggota diberikan kepada pemustaka tertentu sebab masih adanya ikatan persaudaraan dengan pustakawan yang berjaga di layanan sirkularsi, sehingga menimbulkan kecemburuan sosial.

Dalam kejahatan pasti yang faktor yang turut melatarbelakanginya tindakan, tak terkecuali dengan bibliocrime. Terdapat beberapa faktor yang melatarbelakangi perilaku bibliocrime sesuai di perpustakaan, hal ini sesuai juga dengan pendapat Lincoln (1984) yang dikutip (Listiayani, 2010, p. 29) UIN-SU seperti:

- Kemudahan Akses

Kemudahan akses indentik dengan peneran layanan terbuka sehingga pemustakapun bebas mengambil bahan pustaka yang diminatinya. Begitu juga dengan penerapan layanan terbuka di perpustakaan UIN-SU pemustaka diperkenakan untuk mengambil buku yang diinginkanya, hal ini menyebabkan rusaknya susunan yang telah tertata sampai terkadang jatuh akibat brutalnya mobitalis pamustaka khususnya para mahasiswa yang lebih ke berkunjung perpustakaan

- Koleksi yang diminati

Koleksi yang diminati di perpustakaan UIN-SU adalah bukubuku yang terkait dengan mata kuliah para mahasiswa, sehingga karena sangking diminatinya buku-buku kuliah itu akhinya mereka mencuri atau merobek bagian-bagian yang dianggap mereka penting.

- Usia pemustaka

Usia pemustaka yang sering berkunjung ke perpustakaan UIN-SU adalah pemustaka yang berumur antara berusia 18-19 tahun otomatis sifat kenak-kenak mereka masih ada karena itu mereka tak berpikir panjang untuk mencuri ataupun merobek bahan pustaka. 
- Jam buka operasional

Jam Buka perpustakaan UIN-SU masih terbilang jam operasional yang pendek dikarena tutup jam 15.30, oleh karenanya sebagian mahasiswa merasa dongkol karena tidak sesuanya jam kunjung perpustakaan dengan aktivitas mahasiswa yang sampai jam 18.00. Maka hal ini menimbulkan pontensi terjadinya perilaku bibliocrime.

- Kurangnya pengamanan

Kurangnya pengamanan di perpustakaan UIN-SU, terjadi dikarenakan kurang sebadingnya jumlah pemustaka dengan pemustaka yang berkujung ke perpustakaan. Sehingga menjadikan pemicu bagi pemustaka yang ada niatan untuk melakukan kejahan dilingkungan perpustakaan.

- Fasilitas fotocopy

Perpustakaan UIN-SU menyedikan fasilitas focopy guna membantu para pemustaka memperoleh informasi yang diminatinya. Namun fotocopy ini belumlah sesuai dengan harapan para pemustaka, dikerennan sering terjadinya antrian dan juga tak tentunya jam operasi fasilitas fotocopy ini. Sehingga mempengaruhi pemustaka untuk melakukan kejahatan bibliocrime.

- Desain gedung dan tata ruang

Desain dan tata ruang juga turut mempengaruhi perilaku bibliocrime dikarenakan perpustakaan UIN-SU masih ada areaarea yang masih minim pencahayaan, sehingga mempersulit pengawasan.

- Peraturan perpustakaan

Peraturan di perpustakaan UIN-SU ada beberapa yang sudah efektif misalkan larangan membawa makan dan minum ke ruang baca. Tetapi walaupun begitu ada juga peraturan yang tidak ekfetif dan bahkan dianggap remeh 
seperti denda pengembalian buku sebesar 500 rupiah/hari/buku.

Selanjurnya akibat perilaku bibliocrime ini perpustakaan UIN-SU merugi secara sebab harus mengganti buku- buku yang hilang karena pencurian ataupun biaya perbaikan atas kerusakan koleksi, senanda dengan hal itupun (Ajala \& Oyeboade, 2014, p. 23) menyatakan bahwasan perpustakaan sering kehabisan koleksi akibat kejahatan pencurian dan peeobekan, menyebabkan dana yang dimiliki perpustakaan tidak mencukupi untuk melakukan pegantian bahan pustaka.

Tidak hanya dari sisi finanansial yang rugi, tetapi juga aspek sosial perpustakaan karena tidak amannya lingkungan, sehingga membuat perpustakaan menjadi kurang diminati. Untuk itu diperlukanlah upaya penaganan agar perilaku bibliocrime tidak merajalela.

Penanganan yang sudah dilakukan oleh perpustakaan UIN-SU dalam menaggulangi perilaku bibliocrime yaitu:

- Penerapan aturan dan sanksi

Penerapan aturan dan sanksi yang sudah diterapkan di perpustakaan UIN-SU sudah dilakukan seperti denda Rp 500 rupiah, bagi pemustaka yang terlambat mengembalikan buku, pegantian buku jika menghilangkan buku atau merusak buku dan juga larangan membawa makanan dan juga merokok di dalam perpustakaan UIN-SU.

- Himbauan

Dalam mendukung ketertiban di pustakawan UIN-SU senanrti memberian himbauan kepada pemustaka baik secara lisan maupun secara tetulis yang di temple di tempat-tempat strategis yang sering dilalui oleh pemustaka.

- Sistem Keamanan

Sistem keamanan yang ada di perputakaan UIN- SU yaitu personil satpam RFID dan CCTV.

- Satpam 
Setiap hari pihak kemanan UIN-SU mengerahkan salah satu personilnya untuk membantu perpustakaan dalam mengamankan. Tetapi porsonil satpam itu kadang ada dan kadang tidak di lingkungan perpustakaan.

- Radio Frequency Identification (RFID)

RFID Perpustakaan UIN-SU digunakan untuk menjaga bahan pustaka dari tindakan pencurian sebab RFID bisa mendekteksi kepergian koleksi dengan cepat berkat kombinasi radio dan juga microchip yang tempelkan pada sampul bagian belakang, jadi jika koleksi keluar dari lingkungan perpustakaan bisa terdetksi. Senanda dengn itupun (Maryono, 2015, p. 20) berpendapat, "RFID Mempunyai beberapa keuntungan utama melebihi sistem barcode yaitu kemungkinan dibaca secara otomatis tampa memperhatikan garis bahan non konduktor seperti karton kertas dengan kecepatan akses beberapa tag per detik pada jarak $(+100)$ meter". Dan tidak hanya itu saja perpustakaan UIN-SU juga RFID mempergunakan sebagai alat peminjam buku secara elektronik, sehingga dalam meminjam bukupun jadi lebih mudah dan efesien. Senanda dengan (Singh \& Mahajan, 2014, p. 5) hal itupun mengukapkan bahwa dampak positif dari pengunaan RFID adalah menghemat waktu dalam proses sirkularsi.

- Closer Circuit Television (CCTV)

CCTV menjadi hal yang tak terpisahkan, karena mamfaatnya yang bisa memantau gerak-gerik manusia, sehingga berbagai tempatpun memasang CCTV untuk melakukan pemantau, termasuk di perpustakan UIN-SU di pasang CCTV untuk membantu dalam pengamanan. Namun CCTVnya mengalami kerusakan sehingga tak berfungsi dan juga melemahkan sistem keamanan di perpustakaan UIN-SU 


\section{Kesimpulan}

Pasalnya sering kali ditemui berbagai tindakan kejahatan yang amat merugikan dan membuat resah, seperti halnya perpustakaan UIN-SU salah satu perpustakaan yang dimilik Universitas Negeri di Sumatera Utara. Perilaku bibliocrime atau kejahatan perpustakaan tesebut sangat merugikan karena dapat menyebabkan kerawanan di areal perpustakaan.

Kebanyakan pelaku kejahatan perpustakaan adalah mahasiswa yang merupakan pemustaka, mereka biasanya melakukan pencurian, perobekan, vandalisme, peminjaman tak sah yang disebut tindakan bibliocrime. Mereka melakukan hal tersebut atas dasar kebutuhan ekonomi ataupun tuntutan mata kuliah. Selain juga karena kurangnya pengawasan dari pihak perpustakaan akibat kurang sebandingnya jumlah pemustaka dengan pustakawan yang ada, sehingga semakin leluasanya pemustaka melakukan kejahatan. Perilaku tersebut menimbulkan kerugian finansial ataupun kerugian sosial bagi perpustakaan UIN-SU karena diharuskan mengadakan buku pengganti ataupun mengeluarkan biaya perbaikan buku apalagi peralatan perbaikannya masih terbilang tradisional.

Dalam upaya penanganan perilaku bibliocrime, perpustakaan UIN-SU antara lain:

a. Penerapkan peraturan dan sanksi.

b. Pemberian himbauan baik secara lisan ataupun tulisan

c. User Education bagi mahasiswa baru yang berguna untuk mengenalkan berbagai koleksi di perpustakaan dan juga tata tertibnya.

d. Adanya sistem keamanan baik itu satpam, RFID maupun CCTV setiap sudut ruangan.

\section{Saran}

Berdasarkan hasil temuan penelitian, peneliti menyarankan sebagai berikut :

a. Perlunya diadakan pelatihan kepada pustakawan terutama 
mengenai pencegahan perilaku bibliocrime, supaya para pustakawan mengetahui tindakan dan langkah-langkah yang harus dilakukan dalam mencegah terjadinya perilaku bibliocrime.

b. Sistem keamanan agar lebih ditingkatkan lagi supaya dapat meminimalisir terjadinya perilaku bibliocrime, seperti memperbanyak pemasangan dan penempatan CCTV di arealareal rawan kejahatan bibliocrime.

c. Perlu adanya perbaikan sistem penataan buku di dalam rak supaya lebih mempermudah pengawasan.

d. Pemberian sanksi yang tegas bagi para pelaku bibliocrime supaya memberikan efek jera.

e. Jam kunjungan perpustakaan UIN-SU hendaknya diperlama lagi supaya para mahasiswa tidak dongkol karena perpustakaan tutup terlalu cepat.

f. Perluasan lagi areal fasilitas fotocopyan guna mempermudah pemustaka dalam menyalin informasi yang dibutuhkannya. 


\section{DAFTAR PUSTAKA}

Adrimon, T., \& Nalisa, M. (2013). Faktor Peminjaman Tidak Sah (Unauthorized Borrowing) Bahan Pustaka Oleh Pemustaka di Kantor Arsip Perpustakaan dan Dokumentasi Kota Padang. Jurrusan Ilmu Informasi Perpustakaan Padang, 2(1), 7. https://doi.org/DOI : https: / / doi.org/10.24036/2286-0934

Ajala, I. O., \& Oyeboade, S. A. (2014). Theft and Mutilation of Library Materials in Nigerian Academic Libraries. Library \& Archival Security, 21(1), 21-32. https://doi.org/10.1080/01960070802142827

Aprilia, A., \& Sumaryato, Y. (2013). Penyalahgunaan dan Vadalisme terhadap Koleksi: Studi Kasus Perpustakaan Daerah Provinsi DKI Jakarta. Fakutas Imu Budaya,Universitas Indonesia. lib.ui.ac.id/naskahringkas /2016-03/S46127-Anggi\%20Aprilia

Lasa Hs, \& Suciati, U. (2017). Kamus Kepustakawanan Indonesia Edisi 4 (4th ed., Vol. 1). Calopulis.

Listiayani. (2010). Penyalahgunaan Koleksi Perpustakaan: Studi Kasus di Perpustakaan Umum Yayasan LIA Pramuka [Skiripsi, Universitas Indonesia]. lib.ui.ac.id/file?file=digital/20160877-RB13L199pPenyalahgunaan\%20koleksi.pdf

Maryono,. (2015). Dasar-dasar Radio Frequency Identificatio (RFID) Yang Berpengaruh Di Perpustakaan”. Vol. XIV No. 20. Th. 2005, 20.

Obiagwu, M. C. (1992). Library Abuse in Academic Institutions. International $\begin{array}{lllll}\text { Information } \quad \& \quad \text { Library } & \text { Review, }\end{array}$ https: / / doi.org/10.1080/10572317.1992.10762301

Sulistyo-Basuki. (1991). Pengatar Ilmu Perpustakaan (1st ed.). Gramedia Putaka Utama. 